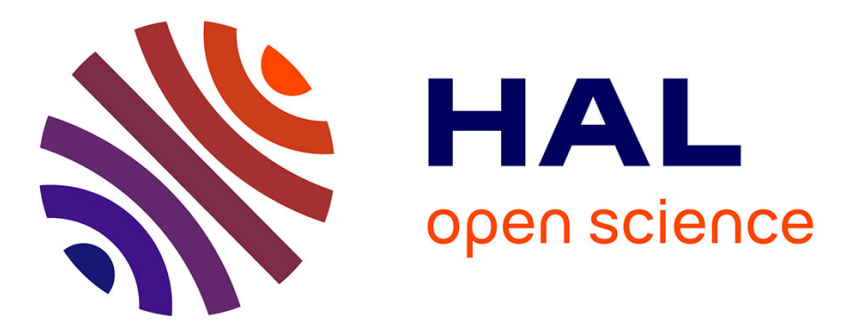

\title{
Magnetooptical Properties of Ce-Doped YIG Single Crystals
}

\author{
J. Ostoréro, M. Escorne, J. Gouzerh, H. Le Gall
}

\section{To cite this version:}

J. Ostoréro, M. Escorne, J. Gouzerh, H. Le Gall. Magnetooptical Properties of Ce-Doped YIG Single Crystals. Journal de Physique IV Proceedings, 1997, 07 (C1), pp.C1-719-C1-720. 10.1051/jp4:19971293 . jpa-00255010

\section{HAL Id: jpa-00255010 https://hal.science/jpa-00255010}

Submitted on 1 Jan 1997

HAL is a multi-disciplinary open access archive for the deposit and dissemination of scientific research documents, whether they are published or not. The documents may come from teaching and research institutions in France or abroad, or from public or private research centers.
L'archive ouverte pluridisciplinaire HAL, est destinée au dépôt et à la diffusion de documents scientifiques de niveau recherche, publiés ou non, émanant des établissements d'enseignement et de recherche français ou étrangers, des laboratoires publics ou privés. 


\title{
Magnetooptical Properties of Ce-Doped YIG Single Crystals
}

\author{
J. Ostoréro, M. Escorne, J. Gouzerh* and H. Le Gall* \\ UPR 209 du CNRS, 1 place A. Briand, 92195 Meudon cedex France \\ * LMIMS du CNRS, 1 place A. Briand, 92195 Meudon cedex, France
}

\begin{abstract}
The Faraday rotation (FR) of cerium substituted yttrium iron garnets single crystals $\mathrm{X}_{3 \times} \mathrm{Ce}_{x} \mathrm{Fe}_{5} \mathrm{O}_{12}$ (YIG:Ce) with $x=0.055$ has been investigated at 1152 and $632.8 \mathrm{~nm}$ in the $6 \mathrm{~K}-600 \mathrm{~K}$ temperature range and magnetic field up to $20 \mathrm{kOe}$ applied along the [111] and [100] directions. In contrast to magnetic properties, the FR of YIG:Ce is strougly different from FR of pure YIG at both wavelengths. The FR contribution of the $\mathrm{Ce}^{3+}$ ions, mainly attributed to intra-ionic electric dipole transitions between the $4 \mathrm{f}^{4}$ and $4 \mathrm{f}^{0} 5 \mathrm{~d}^{1}$ configurations, is discussed within the frame of the one-ion model of ferrimagnetic gamets.
\end{abstract}

\section{1 - INTRODUCTION}

Recently, it has been shown that Ce-substituted yttrium-iron-garnet (YIG:Ce) are very promising magnetooptical (MO) materials both for MO applications and fundamental studies[1-6]. This is due to the specific efficiency of the $\mathrm{Ce}^{3+}$ ions which is much larger than that of $\mathrm{Bi}^{3+}$ ions. Much work deal with the wavelength dependence, at room temperature and fixed magnetic field, of the MO properties of these materials essentially as thin films. We present here the results of the Faraday rotation (FR) of YIG: Ce single crystals at two fixed wavelengths: $1152 \mathrm{~nm}$ (infra red) and $632.8 \mathrm{~nm}$ (visible) as a function of temperature and magnetic field and discuss briefly these results within the frame of the one-ion model[7].

\section{2 - EXPERIMENTAL}

Garnet single crystals of composition $\mathrm{Y}_{3-x} \mathrm{Ce}_{x} \mathrm{Fe}_{5} \mathrm{O}_{12}$ were synthesized by flux growth. Polished oriented platelets were obtained from the "as grown" single crystals. The cerium concentration $x=0.055$, closed to its limit of substitution in YIG garnet synthesized by this method, was measured on the platelets by electron microprobe analysis and checked further by elemental chemical analysis. A small amount of lead was equally incorporated in the crystals $(x<\sim 0.01)$ but no platinum was detected. FR measurements were performed at $\lambda=1152 \mathrm{~nm}$ and $632.8 \mathrm{~nm}$ wavelengths in the $6 \mathrm{~K}-600 \mathrm{~K}$ temperature range under a magnetic field up to $20 \mathrm{kOe}$ applied parallel to the crystallographic axes [100] and [111]. The FR isotherms $\Phi(\mathrm{H}, \lambda)$ present a linear part when $\mathrm{H}>\sim 6 \mathrm{kOe}$ and the spontaneous $\mathrm{FR} \Phi_{\mathrm{s}}$ is obtained by extrapolating to $H=0$ using the relation: $\Phi=\Phi_{\mathrm{s}}+\chi_{\mathrm{F}} \mathrm{H}$, where $\chi_{\mathrm{F}}$ is the FR susceptibility. Magnetization and Curie temperature $T_{c}$ measurements were performed on the same crystals at temperatures between 1.5 and $600 \mathrm{~K}$ using a MANICS DSM10 susceptometer.

\section{3 - RESULTS AND DISCUSSION}

Cerium is incorporated as paramagnetic $\mathrm{Ce}^{3+}$ and diamagnetic $\mathrm{Ce}^{4+}$ ions[2],[5]. Assuming that the $\mathrm{Pb}^{2+}$ ions provide the electric charge compensation, the $\mathrm{Ce}^{3+}$ ions substitution rate is $\mathrm{x}=0.045$ in the YIG:Ce crystals. The measured magnetic properties of the crystals are very close to those of pure YIG: the Curie temperature deduced from the temperature variation of $\mathrm{M}_{\mathrm{s}}^{2}$ in the vicinity of $\mathrm{T}_{\mathrm{C}}$ is the same $(560 \mathrm{~K})$ and furthermore, at $1.5 \mathrm{~K}$ and $300 \mathrm{~K}$ the magnetization of $\mathrm{YIG}: \mathrm{Ce}(\mathrm{Fig}$. 1 ) differs from that of pure YIG by at most $4 \%$. This low difference hinders the determination of the dodecahedral site magnetization of the $\mathrm{Ce}^{3+}$ ions from the magnetic properties as in other rare earth iron garnets[8].

On the contrary, notwithstanding the low Ce substitution rate, a strong enhancement of the FR by comparison to pure YIG is observed at both wavelengths. In the IR at $1152 \mathrm{~nm}$, the FR is negative in the whole temperature range whereas the FR of pure YIG is positive (Fig. 1). At $632.8 \mathrm{~nm}$ wavelength the FR is positive like FR of pure YIG[9] but of very different magnitude particulariy at low temperatures (Fig. 2). It is to be noted that our results are close to those obtained on LPE thin 


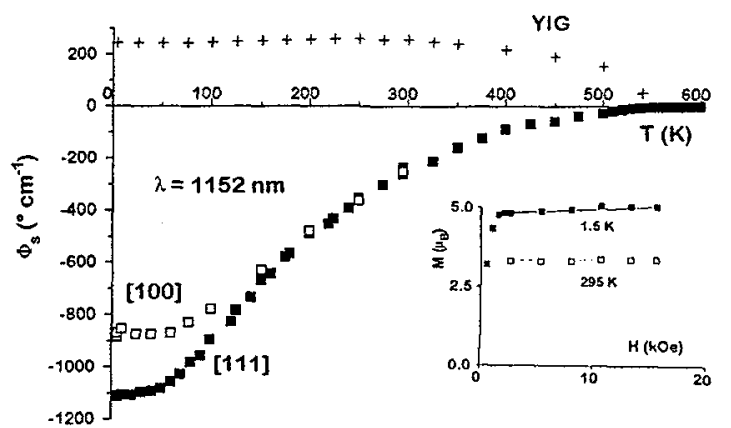

Fig. 1 - Temperature dependence of $\Phi_{\mathrm{s}}$ at $1152 \mathrm{~nm}$ Inset: Magnetization isotherms at $1.5 \mathrm{~K}$ and $295 \mathrm{~K}$



Fig. 2 - Temperature dependence of $\Phi_{\mathrm{B}}$ at $632.8 \mathrm{~nm}$ Inset: Temperature dependence of $\chi_{F}(1152$ and $632.8 \mathrm{~nm})$

films by Kucera et al.[5] at the two temperatures $8 \mathrm{~K}$ and $300 \mathrm{~K}$ with the exception of the Ce substitution rate which was probably underestimated[3]. The $\chi_{F}$ values are negative and quasi constant in the whole temperature range, except near $T_{C}$, for both wavelengths and nearly twice in magnitude at $1152 \mathrm{~nm}$ wavelength as compared to pure YIG (Fig. 2). Below $100 \mathrm{~K}$ an anisotropy of the $\Phi_{s}$ values is observed for both 1152 and $632.8 \mathrm{~nm}$ wavelengths with [100] being the "hard" axis. This FR anisotropy may be due, at least partially, to the magnetic anisotropy of these compounds as evidenced by ferromagnetic resonance method[10].

Both the $\mathrm{Ce}$ and Fe sublattices contribute to the FR. Within the frame of the one-ion model of Crossley et al.[7], the total contribution of the $\mathrm{Fe}^{3+}$ sublattices can be well represented by the FR of pure YIG[8]. The FR contribution of the Ce ${ }^{3+}$ ions in dodecahedral (c) sublattice, mainly attributed to intra-ionic electric dipole transitions between the $4 \mathrm{f}^{1}$ and $4 \mathrm{f}^{0} 5 \mathrm{~d}^{1}$ configurations, is deduced by substracting the FR of pure YIG from the experimental FR of YIG: Ce (Fig. 3). At $300 \mathrm{~K}$, the specific cerium FR is $-1.110^{4}$ and $1.510^{4} \% \mathrm{~cm} / \mathrm{Ce}^{3+}$ at respectively 1152 and $632.8 \mathrm{~nm}$. The Ce $\mathrm{Ce}^{3+}$ contribution is given by [7], [8]: $\Phi_{c}(\mathrm{~T}, \lambda)=\left[\mathrm{C}_{\mathrm{m}}+\mathrm{C}_{\mathrm{e}}(\mathrm{T}, \lambda)\right]\left|\mathrm{M}_{\mathrm{c}}(\mathrm{T})\right|$ where $\mathrm{C}_{\mathrm{m}}$ and $\mathrm{C}_{\mathrm{s}}$ are the $\mathrm{MO}$ coefficients due to magnetic(m) and electric $(\mathrm{e})$ dipole transitions. The temperature variation of the reduced FR $\Phi_{c}(T, \lambda) / \Phi_{c}(0, \lambda)$ is plotted in Fig. 3 for both wavelengths. When $T<350 \mathrm{~K}$, the two curves are nearly the same within experimental accuracy indicating a similar temperature dependence of the reduced $M O$ coefficient $\left[C_{m}+C_{e}(T, \lambda)\right] /\left[C_{m}+C_{c}(0, \lambda)\right]$ at these wavelengths. In the absence of experimental values, the

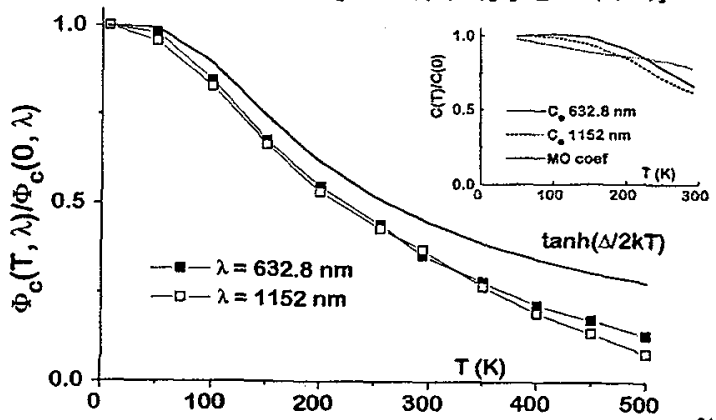
reduced magnetization can be calculated using $\mathrm{M}_{c}(\mathrm{~T}) / \mathrm{M}_{0}(0)=\tanh (\Delta / 2 \mathrm{kT})$ where $\Delta=200 \mathrm{~cm}^{-1}$ is the average splitting of the Kramers doublet of the ground state ${ }^{2} F_{5 / 2}$ in the exchange field[11]. We plotted in Fig. 3 the temperature variation of the reduced $\mathrm{MO}$ coefficient and aiso the temperature dependence of $\mathrm{C}_{e}(\mathrm{~T}, \lambda) / \mathrm{C}_{\mathrm{e}}(\mathrm{T}=50 \mathrm{~K}, \lambda)$ for both wavelengths caculated by $\mathrm{Xu}$ et al.[3] in the $50-294 \mathrm{~K}$ temperature range. The similarity of the different curves both in magnitude and temperature variation confirms that the electric dipole transitions contribution to $\mathrm{FR}$ of $\mathrm{Ce}^{3+}$ ions is predominant[3], [6].

Fig. 3 - Temperature dependence of the reduced FR of the $\mathrm{Ce}^{3+}$ ions.

Inset: Reduced MO coefficient and calculated $\mathrm{C}_{e}(\mathrm{~T}, \lambda) / \mathrm{C}_{e}(50, \lambda)[3]$

\section{References}

[1] Diercks Jr. G.J. and Samuelson S., DEEE Trans. Mag. 31 (1995) 3328-3330

[2] Okamura Y., Kubota J. and Yamamoto S., IEEE Trans. Mag. 31 (1995) 3289-3291

[3] Xu Y., Yang J.H. and Zhang X.J., Phys. Rev. B 50 (1994) 13428-13434

[4] Gomi M., Furuyama H. and Abe M., J. Appl. Phys. 70 (1991) 7065-7067

[5] Kucera M., Bok J. and Nitsch K., Solid State Comm. 69 (1989) 1117-1121

[6] Leycuras C., Le Gall H., Desvignes J.M., Guillot M. and Marchand A., IEEE Trans. Mag. 21 (1985) 1660-1662

[7] Crossley W.A., Cooper R.W., Page J.L., Van Stapele R.P., Phys. Rev. 181 (1969) 896-904

[8] Guillot M., Marchand A., Le Gall H., Feldmann P. and Desvignes J.M., J. Mag. Magn. Mat. 15-18 (1980) 835-836

[9] Hansen P. and Krumme J.P., Thin Solid Films 114 (1984) 69-107

[10] Belov K.P., Volkova N.V., Raitsis V.I., Soviet Phys. Solid State 15 (1973) 612-613

[11] Comstock R.L. and Raymond J.J., J. Appl. Phys. 38 (1967) 3737-3739 